This item was submitted to Loughborough's Research Repository by the author.

Items in Figshare are protected by copyright, with all rights reserved, unless otherwise indicated.

\title{
Hydraulic actuation technology for full- and semi-active railway suspensions
}

PLEASE CITE THE PUBLISHED VERSION

http://dx.doi.org/10.1080/00423114.2014.953181

PUBLISHER

(C) Taylor \& Francis

VERSION

AM (Accepted Manuscript)

\section{PUBLISHER STATEMENT}

This work is made available according to the conditions of the Creative Commons Attribution-NonCommercialNoDerivatives 4.0 International (CC BY-NC-ND 4.0) licence. Full details of this licence are available at: https://creativecommons.org/licenses/by-nc-nd/4.0/

\section{LICENCE}

CC BY-NC-ND 4.0

\section{REPOSITORY RECORD}

Goodall, Roger M., Gerhard Freudenthaler, and Roger Dixon. 2019. "Hydraulic Actuation Technology for Fulland Semi-active Railway Suspensions". figshare. https://hdl.handle.net/2134/22054. 


\section{HYDRAULIC ACTUATION TECHNOLOGY FOR FULL- AND SEMI-ACTIVE RAILWAY SUSPENSIONS}

Roger Goodall

Loughborough University, Loughborough, LE11 3TU, UK

Gerhard Freudenthaler

Technical University of Vienna, Austria

Roger Dixon $\uparrow$

Loughborough University, Loughborough, LE11 3TU, UK

Corresponding author: Roger Goodall, r.m.goodall@lboro.ac.uk, Loughborough University, Loughborough, LE11 3TU, UK 


\title{
HYDRAULIC ACTUATION TECHNOLOGY FOR FULL- AND SEMI-ACTIVE RAILWAY SUSPENSIONS
}

\begin{abstract}
The paper describes a simulation study that provides a comprehensive comparison between full-active and semi-active suspensions for improving the vertical ride quality on railway vehicles. It includes an assessment of the ride quality benefits that can theoretically be achieved with idealised devices, and also examines the impact of real devices based upon hydraulic actuation technology.
\end{abstract}

Keywords: Mechatronics, active suspension, actuator, secondary suspension, railway vehicle, simulation

\section{INTRODUCTION}

In the last two decades, much research has been completed in order to improve ride quality on railway vehicles. An overall summary of the possibilities of using active suspensions for railway vehicles is included in [1], and it is generally accepted that such concepts applied to the secondary suspension system offer significant improvements in ride quality, including the effects of different actuator technologies - see for example [2, 3]. Tilting trains, which are an example of active suspension technology, represent what is nowadays a standard railway technology which is offered and supplied by all major rail vehicle manufacturers in high-speed trains and for regional applications [1]. However a broader use of active secondary suspensions has been very limited. This is largely because a higher level of passenger comfort is not strongly cost beneficial, and since semi-active devices are cheaper and simpler a number of workers have investigated the use of these both theoretically and via experiment (see for example [4, 5]).

Full-active and semi-active approaches have a significant difference. A full-active approach includes a fully-controllable force actuator that includes a power supply, whereas the 
semi-active concept utilises a suspension component with a controllable characteristic. The energy flow of a semi-active suspension is controlled but not augmented, and furthermore the energy flow's direction is limited to one direction. More precisely, it is only possible to dissipate energy but not inject it (although with an accumulator it is possible to partly utilize the energy stored [6]), and this behaviour results in a fundamentally nonlinear concept which offers less improvement compared with full-active. In principle any passive component whose characteristics can be changed electrically would comprise a semi-active device, but in practice a semi-active actuator is usually a conventional damper with the ability of variable damping by using electro hydraulic or electro-rheological fluid devices. On the other side, full-active actuators mostly use electro-hydraulic, pneumatic or electro-mechanical technology. Electroand magneto-rheological fluids have also been studied for semi-active devices, but at present these are not appropriate for the actuation required for full-active suspensions.

The papers referenced above [1-5] are examples of many studies of both full-active and semi-active suspensions for improving the ride quality on railway vehicles, but none has properly compared their relative performance using a consistent set of

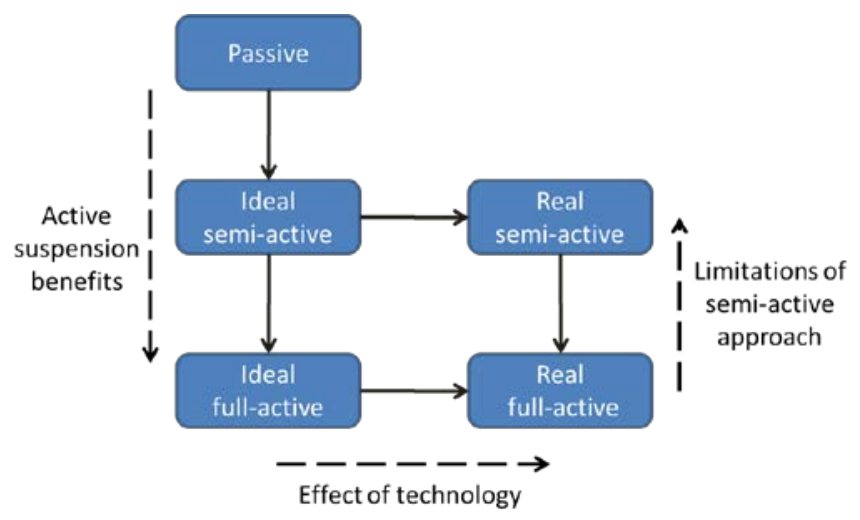

Fig 1 Assessment framework criteria. It has also not been possible to define what can theoretically be achieved with idealised devices compared with real active and semi-active hydraulic actuation. This paper provides a consistent comparative assessment for a vertical suspension system based upon a "side-view" suspension model for a four-axle vehicle focussed upon the comparisons as indicated by Fig 1. The passive v. semi-active v. full-active comparison identifies the conceptual benefits of active control, and provides an aspirational basis for possible developments in actuator technology for 
active suspensions, including the fundamental limitations of semi-active compared with active solutions. The ideal v. real comparison, in this paper for a single technology, moderates expectations of what is achievable in practice and perhaps guides technology improvements.

\section{MODELLING AND ASSESSMENT}

This section describes the simulation models for the vehicle suspension and the full- and semi-active devices used in the study, and also explains the requirements and approach used for assessment.

\subsection{Sideview vehicle model}

The simulation studies are undertaken using a passive side-view model that includes four axles, two bogies and primary and secondary vertical suspensions shown by Fig. 2. Typical parameters for a modern high-speed train with an airspring suspension are used [7] (notation, equations and values are listed in the Appendix). Note that, for both the full- and semi-active solutions, the surge reservoir and orifice damping represented by $\mathrm{k}_{\mathrm{Sec}}$ and $\mathrm{c}_{\mathrm{Sec}}$ are omitted since damping is then provided through active control. The corresponding equations are not included here because they have been adequately described by many papers. 


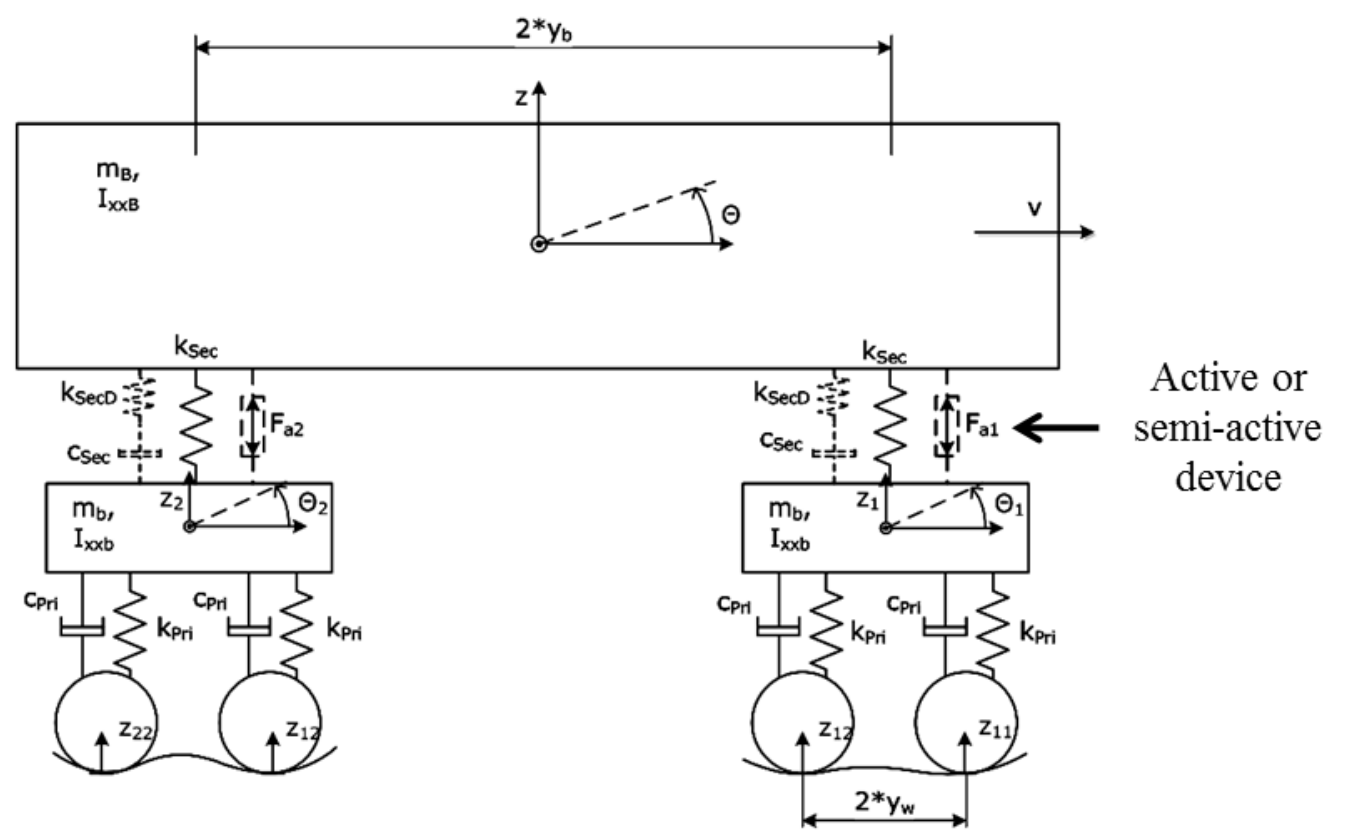

Fig 2 Side view model of railway vehicle

\subsection{Full and semi-active device models}

The actuators are fitted in parallel with the secondary suspension as indicated in Fig 2, and their modelling requires different approaches for each of the four options. The ideal full-active actuator is simply a perfect force actuator that generates the commanded force irrespective of the movements across it and with no time delay. It can produce bi-directional force when the actuator is moving in both directions, i.e. it can operate in all four quadrants of the force-velocity graph, although a real actuator will of course be subject to dynamic constraints relating to how quickly it can transition from one quadrant to another.

However even the ideal semi-active damper is a non-linear device with a force/velocity coefficient that can be varied instantly up to a maximum defined value - more discussion of this is given below. However this is not true for the semi-active device, and Figure 3 provides a generalised characteristic which illustrates that it is constrained to operate in a relatively small area of the graph. Not only is operation in the upper left and lower right quadrants completely impossible, but also the minimum and maximum damping rates provide a limitation in the other 
two quadrants. This type of characteristic emphasises the fundamentally non-linear nature of all semi-active suspensions.

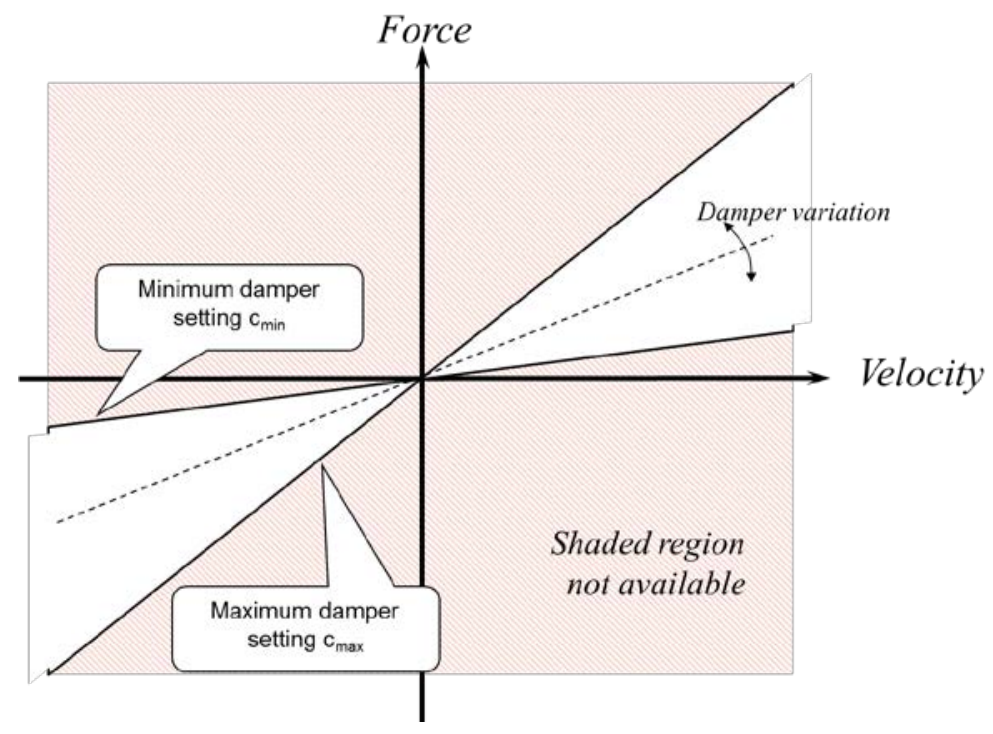

Fig 3 Semi-active damper Force-Velocity characteristic

For the "real" actuator a well-established model described by Neal [8] is depicted in Fig. 4. The equations that are used to represent the compressibility of the oil in the cylinder and the nonlinear flow/pressure relationship associated with the servo-valve are given in the Appendix, also based upon Neal's well-established approach. The corresponding linearised block diagram model is given by Figure 5, which includes a no flow pressure gain $\mathrm{K}_{\mathrm{c}}$ and a transfer function to allow for the valve dynamic response.

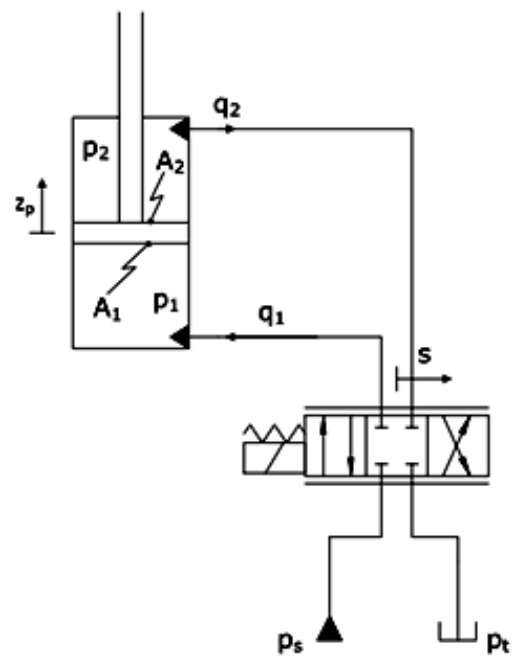


Fig 4 Real hydraulic actuator scheme

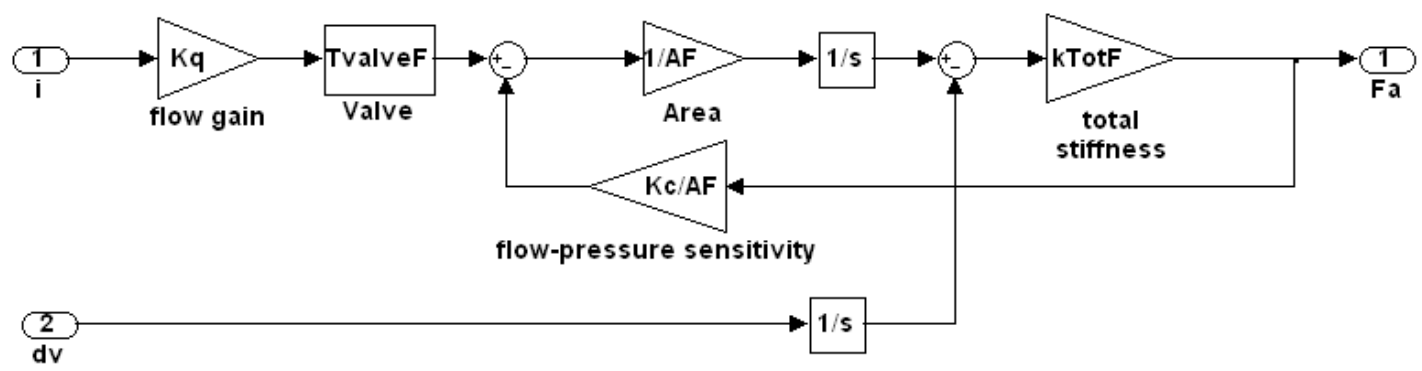

Fig 5 Real hydraulic actuator linearised block diagram

The "real" semi-active device is a relatively straightforward adaptation of the full-active hydraulic model, but without the hydraulic power supply, as shown in Fig 6. The valve is then a simple variable device connected between the two sides of the actuator. Although in principle it is possible to account for the different effective areas by shaping the opening characteristics of the valves, for this study a "through-rod" actuator has been assumed so that, unlike the full-active actuator, the flows are equalised. The same flow/pressure relationship as the full actuator is used.

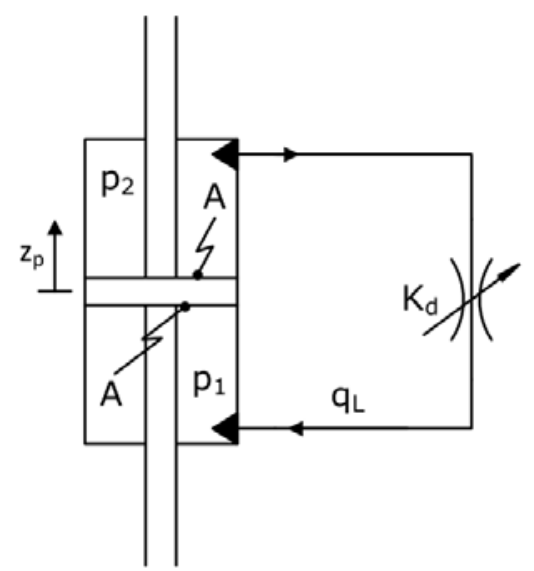

Fig 6 Semi-active damper scheme

By means of simulations with the ideal full active suspension it was possible to undertake an 
“outline design”, and this defined actuator force and velocity requirements of $15 \mathrm{kN}$ and $0.4 \mathrm{~m} / \mathrm{s}$ respectively. A supply pressure of 210 bar was assumed, and these values enabled the calculation of other parameters, e.g. the area of the piston, and to choose an appropriate cylinder and valve. Parameter values based upon this outline hydraulic design process are listed in the Appendix.

\subsection{Performance assessment approach}

The secondary suspension of a railway vehicle has to cope with deterministic and stochastic disturbances. The former are caused by guiding the vehicle along the intended track variations, such as gradients or curves. The latter occur due to track irregularities. The design aim is to limit the maximum suspension deflection for the deterministic input, while isolating the stochastic component and achieving the best possible ride quality. It should be emphasised that the maximum suspension deflection is often not considered for a normal passive suspension, but this does become an important constraint with the active suspension control strategies, which are most appropriately based upon absolute or "skyhook" damping [9].

\section{Track irregularities}

Although it is possible to use real measured track irregularities to give predictions for a real section of track, for a research assessment a generalised simplified power spectrum to represent track irregularities can be used [9] which provides a good representation of the irregularities in the range $0.1-10 \mathrm{~Hz}$, although it over-emphasises their size at higher frequencies.

$$
\mathrm{S}_{\mathrm{t}}\left(\mathrm{f}_{\mathrm{t}}\right)=\frac{A_{v}}{f_{t}^{2}}
$$

where $A_{v}$ is the track roughness factor and $f_{t}$ is a spatial frequency [cycles/m]. Using the speed of the train $\mathrm{v}$ this can be converted to a temporal frequency and the track vertical velocity input 
modelled by a band-limited Gaussian white noise with a flat spectrum given in Equation 2, where the units are now $\left(\mathrm{ms}^{-1}\right)^{2} / \mathrm{Hz}$.

$$
\mathrm{G}_{\dot{\mathrm{Z}}_{\mathrm{t}}}(f)=(2 \pi)^{2} A_{v} v
$$

The roughness factor was taken as $1 \times 10^{-7} \mathrm{~m}$ and the velocity as $55 \mathrm{~m} / \mathrm{s}$, i.e. to represent typical conditions for a $200 \mathrm{~km} / \mathrm{h}$ train. Appropriate speed-dependent time delays are used to provide the inputs to the other three axles of the vehicle.

Ride quality has been assessed using RMS acceleration values. It would be possible to use frequency weighting to allow for human susceptibility to vibration, for example as specified by ISO 2631, but in fact unweighted accelerations are used in this study.

\section{Deterministic input}

A gradient of $2 \%$ was assumed as the deterministic input, which included a transition section having a superimposed vertical acceleration of $0.3 \mathrm{~m} / \mathrm{s}^{2}$. Obviously these values will vary between different administrations and routes, but represent a typical worst case for which the suspension control might have to be designed.

\section{DEFINITION OF CONTROL STRATEGIES}

There are two distinct issues to be described: firstly the basic suspension control strategy which generates active force commands that are appropriate to provide ride quality improvements; secondly, when the actuator is non-ideal, the inner loop that achieves force control of the actuator (Figure 5). These two issues are explained in the following sub-sections. 


\subsection{Suspension control strategies}

Although there is a wide variety of active secondary suspension control possibilities that have been described, in one way or another they normally employ the concept of "skyhook" damping, or absolute velocity damping (which is a more scientific description). Both the fulland semi-active controllers used for this analysis are based upon skyhook damping, although each has important variations, and Figures 7-10 describe the progressive development of the basic skyhook strategy to accommodate the different practicalities.

\section{Full-active control}

A practical skyhook control strategy involves modifying the basic skyhook concept in two important ways:

i. Pure absolute velocity damping creates large suspension deflections on track gradients (or curves for an active lateral suspension), and it is necessary to include a high-pass filter to remove the inputs associated with such features [9]. This filter diminishes the improvements that are possible, but is essential to meet the maximum deflection constraint. Normally the absolute velocity measurement is derived by integrating the signal from an accelerometer, and in order to avoid integrator drift it is practical to combine with the high-pass filter (Figure 7), in other words the high-pass effect serves two purposes. Cut-off frequency of $0.16 \mathrm{~Hz}$ (1 rad/s) has been used, the same as in [9].

ii. Applying the damping in modal sense (bounce and pitch for a vertical suspension) is beneficial for ride quality, as shown in Figure 8. This is because it is possible to use a higher skyhook damping coefficient in the pitch mode than the bounce mode, a consequence of the deterministic input into the pitch mode being much smaller. 


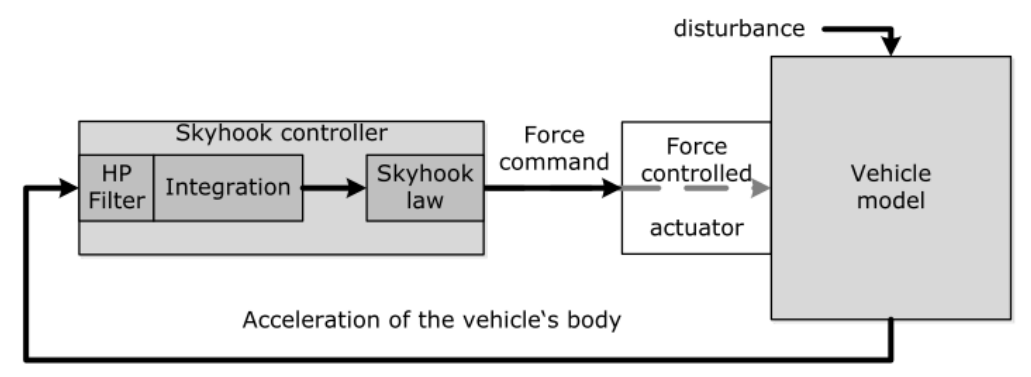

Fig 7 Scheme of the skyhook damping suspension controller

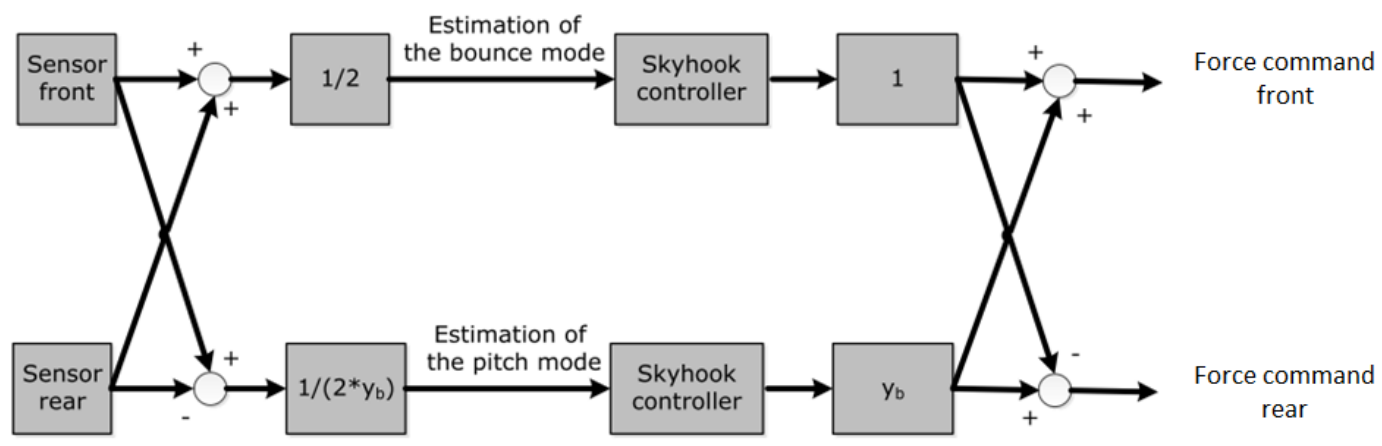

Fig 8 Scheme of modal skyhook control strategy [new figure]

\section{Semi-active control}

The same suspension control strategy can be used but it's necessary to convert the force command into a control signal for the semi-active device, essentially a damper setting, and Figure 9 illustrates the way that this can be done, also taking into account the maximum and minimum damping rate limits available for the device. Due to the division by actuator velocity, the demanded damping rate may clearly become very large, but the controller prevents this by means of the maximum limit (although the program code would need to have overflow and divide by zero protection). 


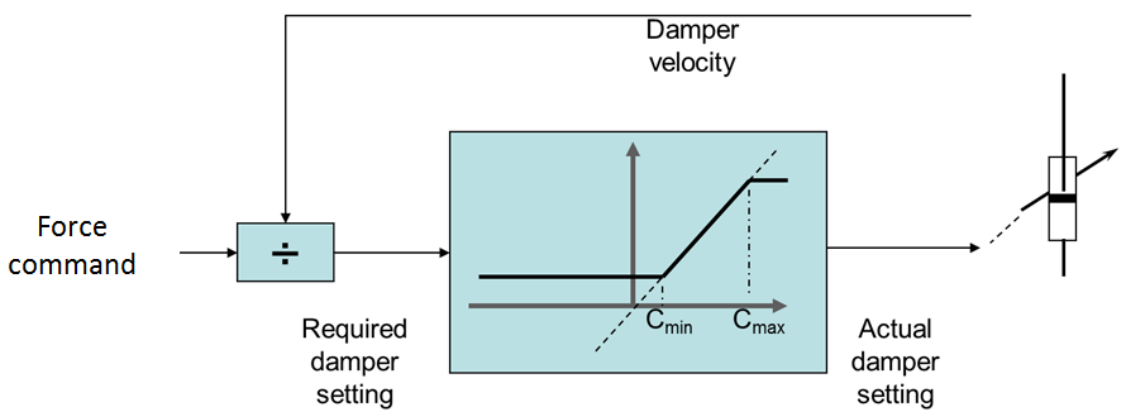

Fig 9 Basic semi-active control strategy [new figure]

\subsection{Real actuator control}

Actuator for full-active suspension

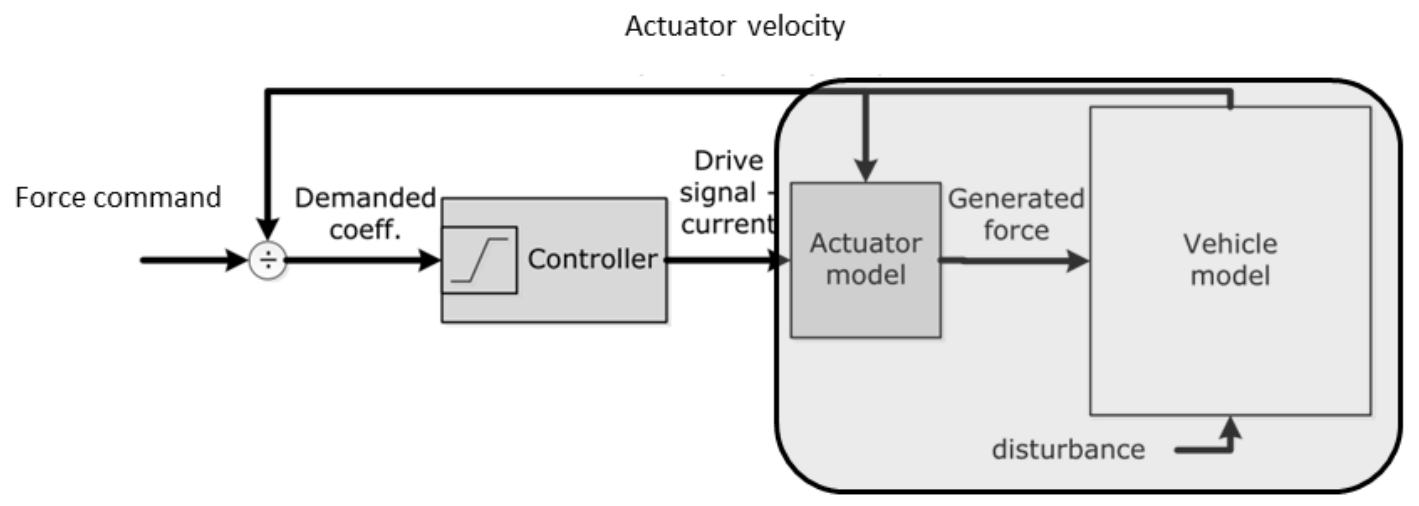

Figure 10 Real actuator controller [new figure]

Figure 10 shows the scheme for a force-feedback controller. Achieving fast control action is a challenge for the design of the controller itself. Since the controller has a relatively low gain, high force errors are needed to produce enough flow, but the suspension strategy demands very small force at high frequency to provide a good ride quality, and these two requirements are in conflict. Better performance can be achieved by including a spring in series with the actuator, and a spring with a stiffness $\mathrm{k}_{\mathrm{sec}}$ of 20 times the secondary suspension stiffness $\mathrm{ks}_{\mathrm{ec}}$ was used - 
essentially this is in series with the compressibility of the oil in the actuator chambers. A corresponding integral plus phase advance controller was designed based upon optimising the force tracking performance of the inner loop. The parameters both for the force controller and for the "modal skyhook" suspension controller are given in the Appendix.

\section{Semi-active device}

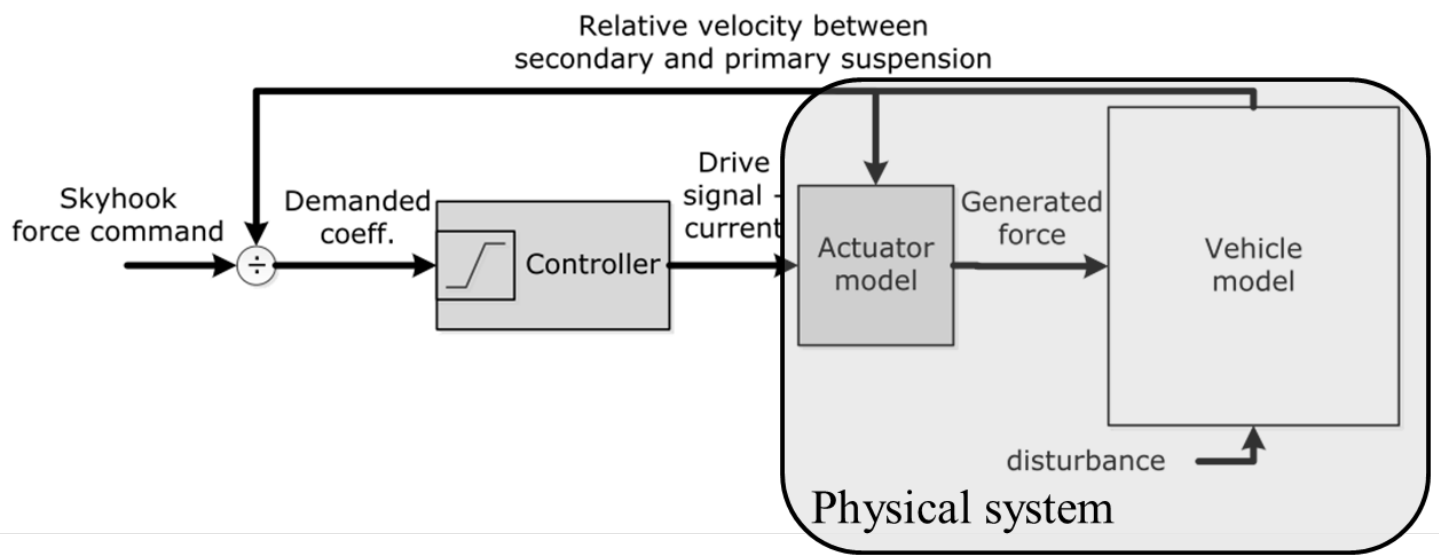

Figure 11 Scheme of the real semi-active device controller

Figure 11 shows the controller used for the semi-active device, including the actuator model as previously described. The skyhook force command is generated using the same controller as for the full-active solution. The scheme of Fig 9 is used to define the required damping constant, with $\mathrm{c}_{\min }$ and $\mathrm{c}_{\max }$ defined as $0.2 \mathrm{c}_{\mathrm{sec}}$ and $2 \mathrm{c}_{\mathrm{sec}}$ respectively. (The relationship between valve current and damping constant is derived using the damper equations assuming a very high value of series stiffness.)

\section{SIMULATION STUDIES}

A large number of simulations involving both time and frequency domain analysis were undertaken to determine optimum settings for the various parameters and the values used for the suspension controller (bounce and pitch skyhook damping values, high-pass filter cut-off 
frequency) are listed in the Appendix.

\subsection{Time domain results}

Table 1 shows the overall performance comparison derived from the time domain simulation, both in absolute RMS acceleration and percentage change (negative is an improvement in ride quality), with the ride quality of the passive suspension as a reference. It can be seen both that full-active always out-performs the semi-active approach, and also that adding "real” actuator technology inevitably provides some degradation. The percentage figures highlighted in grey indicate the size of this degradation, real v. ideal.

The table emphasises the crucial benefit when using active control. It shows that the improvement at the front and rear of the vehicle is significantly higher than in the middle, with the rear of the vehicle benefitting from the highest improvement (although in terms of absolute values the rear starts off as the worst).

Table 1 Ride quality and suspension deflection results from time simulation

\begin{tabular}{|c|c|c|c|c|c|c|c|c|c|c|c|}
\hline & \multicolumn{9}{|c|}{ RMS values of the body vertical acceleration (\%g) } & \multicolumn{2}{|c|}{$\begin{array}{l}\text { Max defl. } \\
\text { (mm) }\end{array}$} \\
\hline & & Front & & & Centre & & & Rear & & Front & Rear \\
\hline & RMS & $\begin{array}{l}\text { \%age } \\
\text { Real v. } \\
\text { ideal }\end{array}$ & $\begin{array}{l}\text { \%age v. } \\
\text { passive }\end{array}$ & RMS & $\begin{array}{l}\text { \%age } \\
\text { Real v. } \\
\text { ideal }\end{array}$ & $\begin{array}{l}\text { \%age v. } \\
\text { passive }\end{array}$ & RMS & $\begin{array}{l}\text { \%age } \\
\text { Real v. } \\
\text { ideal }\end{array}$ & $\begin{array}{l}\text { \%age v. } \\
\text { passive }\end{array}$ & & \\
\hline Passive & 3.14 & & $\neg$ & 1.65 & & $\neg$ & 3.58 & & $\neg$ & & \\
\hline Ideal full & 1.41 & $\neg$ & $-55.1 \%$ & 1.02 & $\neg$ & $-38.2 \%$ & 1.51 & $\neg$ & $-57.2 \%$ & 28.5 & 25.9 \\
\hline Real full & 1.70 & $+20.6 \%$ & $-45.9 \%$ & 1.16 & $+13.7 \%$ & $-29.7 \%$ & 1.78 & $+17.9 \%$ & $-50.3 \%$ & 28.5 & 25.4 \\
\hline Ideal semi & 1.94 & $\neg$ & $-38.2 \%$ & 1.31 & $\neg$ & $-20.6 \%$ & 2.02 & $\neg$ & $-43.6 \%$ & 24.9 & 24.4 \\
\hline Real semi & 2.06 & $+6.2 \%$ & $-34.4 \%$ & 1.37 & $+4.6 \%$ & $-17.6 \%$ & 2.13 & $+5.4 \%$ & $-40.5 \%$ & 24.8 & 24.1 \\
\hline
\end{tabular}


Since the full-active suspension system is entirely linear the RMS values can also be derived analytically based upon frequency response analysis and using a calculation of the transfer function from disturbances to acceleration with the inner force and outer skyhook loops closed. The RMS values are given by

$$
a_{R M S}=\sqrt{\int_{0}^{\infty}|H(j \omega)|^{2} \mathrm{G}_{\dot{\mathrm{z}}_{\mathrm{i}}}(j \omega) d \omega}
$$

where the transfer function $H(j \omega)$ has to include the speed-dependent time delay information between track input and the four wheel sets, i.e.

$$
H(j \omega)=H_{0}(j \omega)+\sum_{i=1}^{3} H_{i}(j \omega) e^{-j \omega \frac{y_{i}}{v}}
$$

Table 2 gives these analytical results for the full-active system, which shows an excellent match with the corresponding results in Table 1 . As already mentioned the semi-active skyhook control law is highly non-linear and so the same analysis cannot be applied to the semi-active suspension.

\begin{tabular}{|c|c|c|c|c|c|c|}
\hline & \multicolumn{6}{|c|}{ RMS values of the body's vertical acceleration in \%g } \\
\hline & Front & & Centre & & Rear & \\
\hline & RMS & $\begin{array}{l}\text { \%age v. } \\
\text { Passive }\end{array}$ & RMS & $\begin{array}{l}\text { \%age v. } \\
\text { Passive }\end{array}$ & RMS & $\begin{array}{l}\text { \%age v. } \\
\text { Passive }\end{array}$ \\
\hline Passive & 3.11 & $\neg$ & 1.60 & $\neg$ & 3.55 & $\neg$ \\
\hline Ideal full & 1.39 & $-55.3 \%$ & 1.00 & $-37.1 \%$ & 1.48 & $-58.3 \%$ \\
\hline Real full & 1.69 & $-45.7 \%$ & 1.15 & - 28.8\% & 1.76 & $-50.5 \%$ \\
\hline
\end{tabular}

Table 2 RMS body acceleration and relative benefits - values based on analytical calculations

\subsection{PSD Analysis}

Power spectral density information has also been investigated (partly in the process of optimising the control schemes). Of course this reflects what has been seen in previous active 
suspension studies, but it is useful to include some results in order to show where the various benefits are achieved in terms of different frequencies. In all cases the comparisons are based upon acceleration PSDs over the rear suspension of the vehicle.

Figure 12 shows the passive vehicle response in comparison with ideal full-active and ideal semi-active, which shows the profound improvements that are possible with both types of active suspension. Figure 13 omits the passive response and gives a clearer view of the additional improvements achievable with full-active: the semi-active solution gives slightly reduced acceleration levels at low frequencies below about $0.6 \mathrm{~Hz}$, whereas the full-active is superior for higher frequencies.

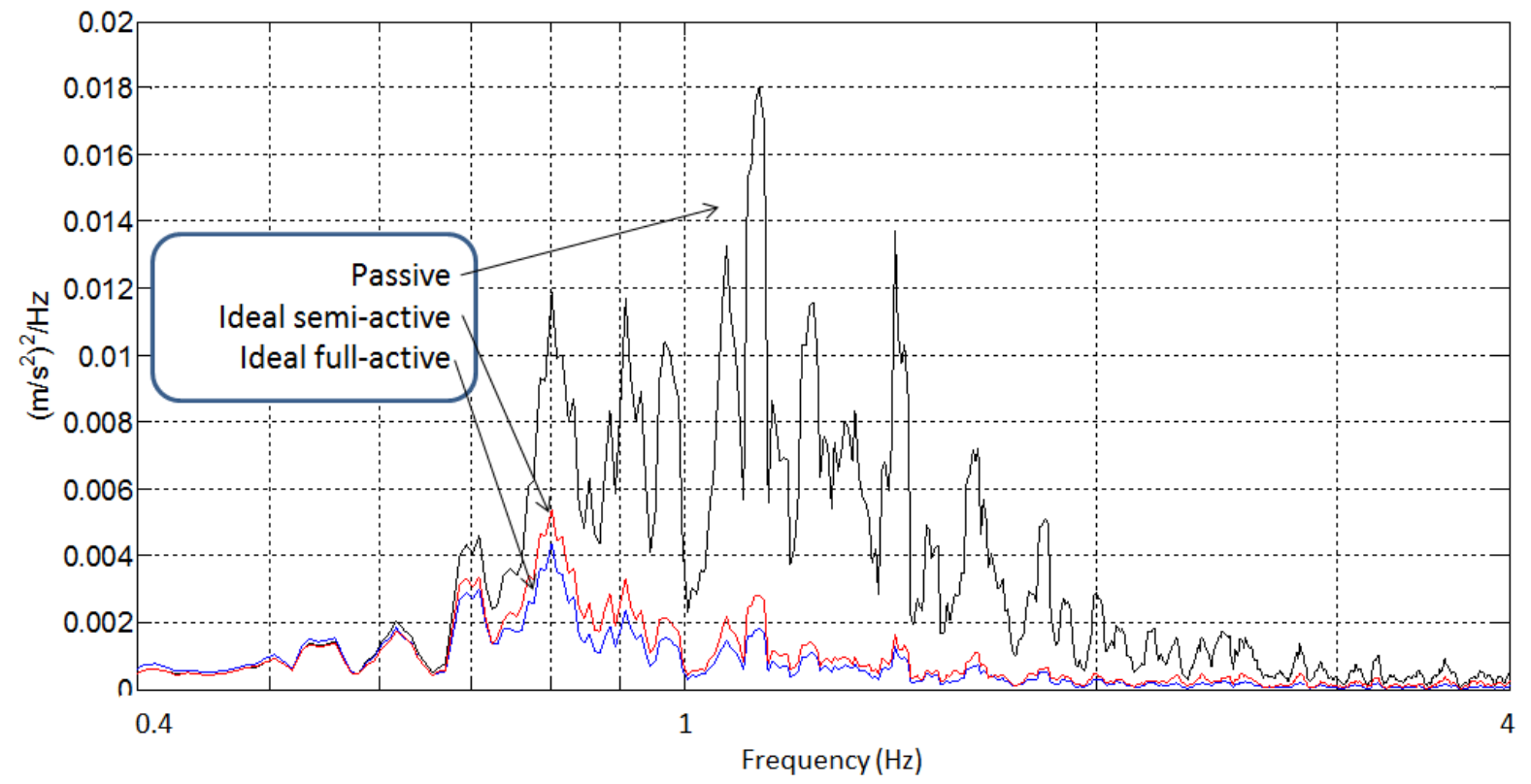

Fig 12 Acceleration PSDs at rear of vehicle, passive v. ideal full- and semi-active 


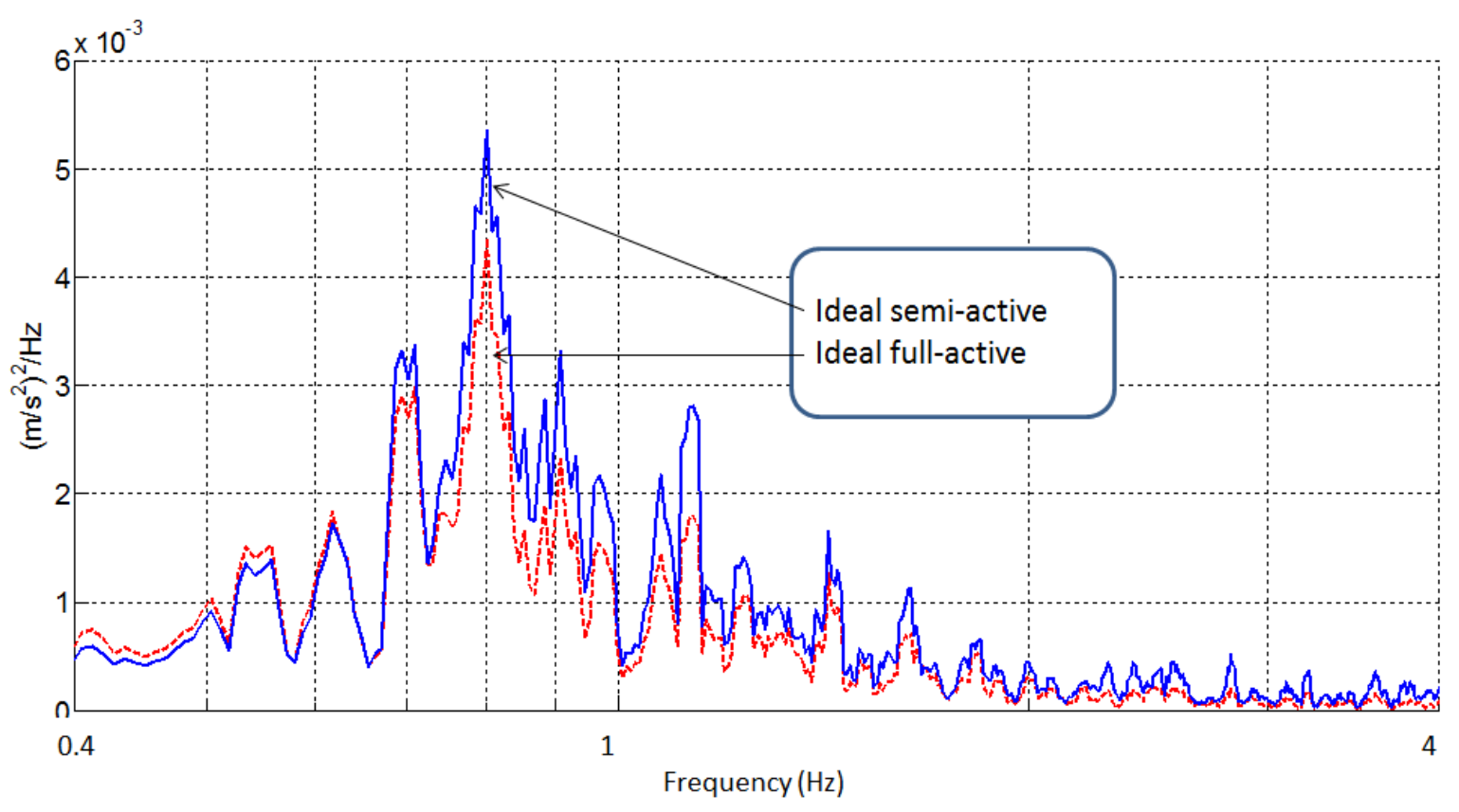

Fig 13 Acceleration PSDs at rear of vehicle, ideal full- and semi-active

Figures 14 and 15 show the effects of real actuator technology. Very little difference is seen for the real semi-active solution in Figure 14, which reflects the small degradation of 5.4\% listed in Table 1, whereas Figure 15 shows a larger change for the real full-active, Table 1 indicating a $17.9 \%$ degradation. Note that from $1-3 \mathrm{~Hz}$ the real actuator is slightly better, but the degradation arises from the higher accelerations which can just be seen beyond $5 \mathrm{~Hz}$, but the true impact is obscured by the restricted logarithmic frequency axis: Figure 16 has a linear axis extending from $10 \mathrm{~Hz}$ to $30 \mathrm{~Hz}$ and shows that the degradation occurs at higher frequencies, particularly around $20 \mathrm{~Hz}$, a problem that doesn’t happen with the real semi-active solution, results for which are shown in Figure 17. 


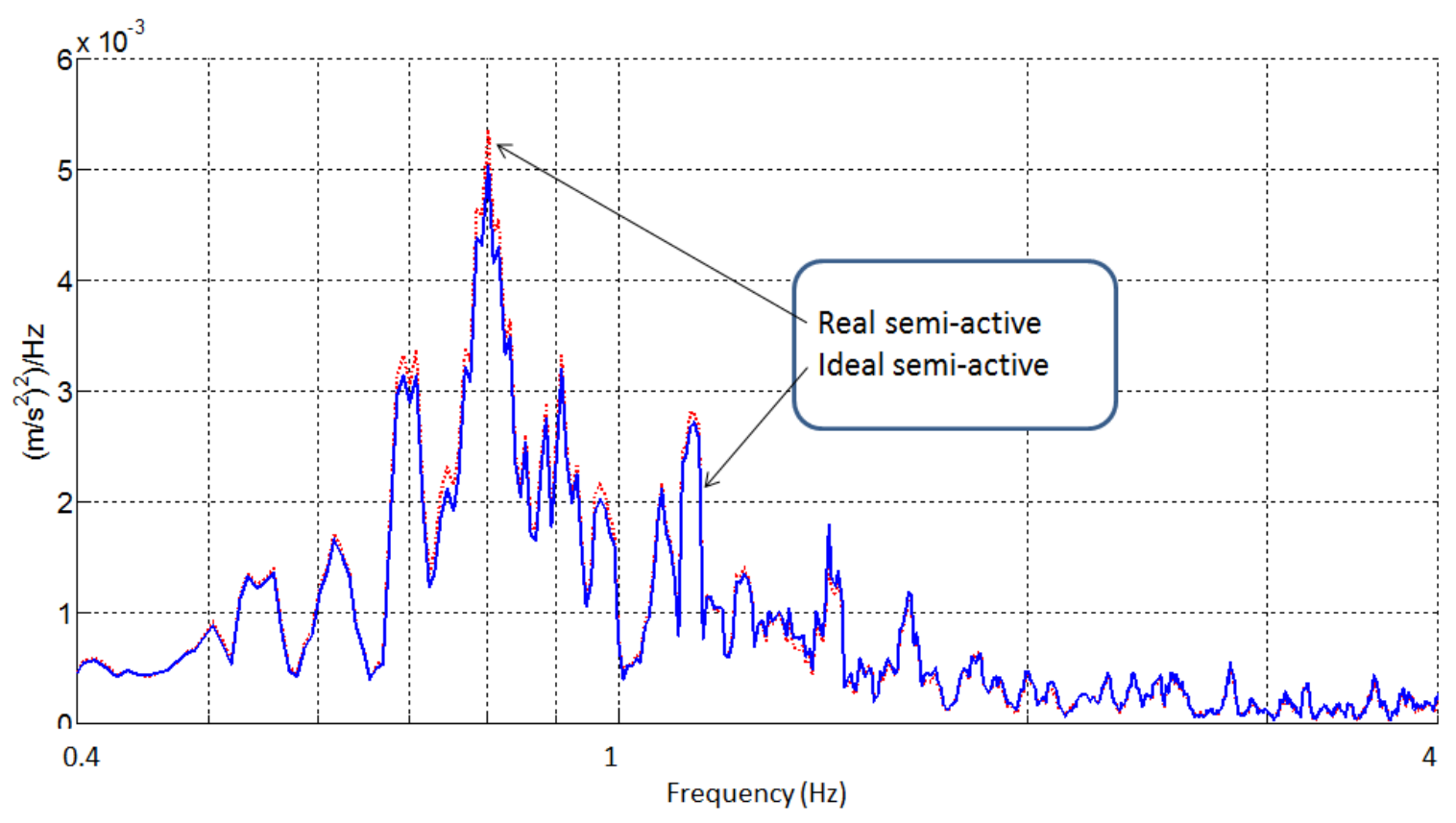

Fig 14 Acceleration PSDs at rear of vehicle, ideal v. real semi-active

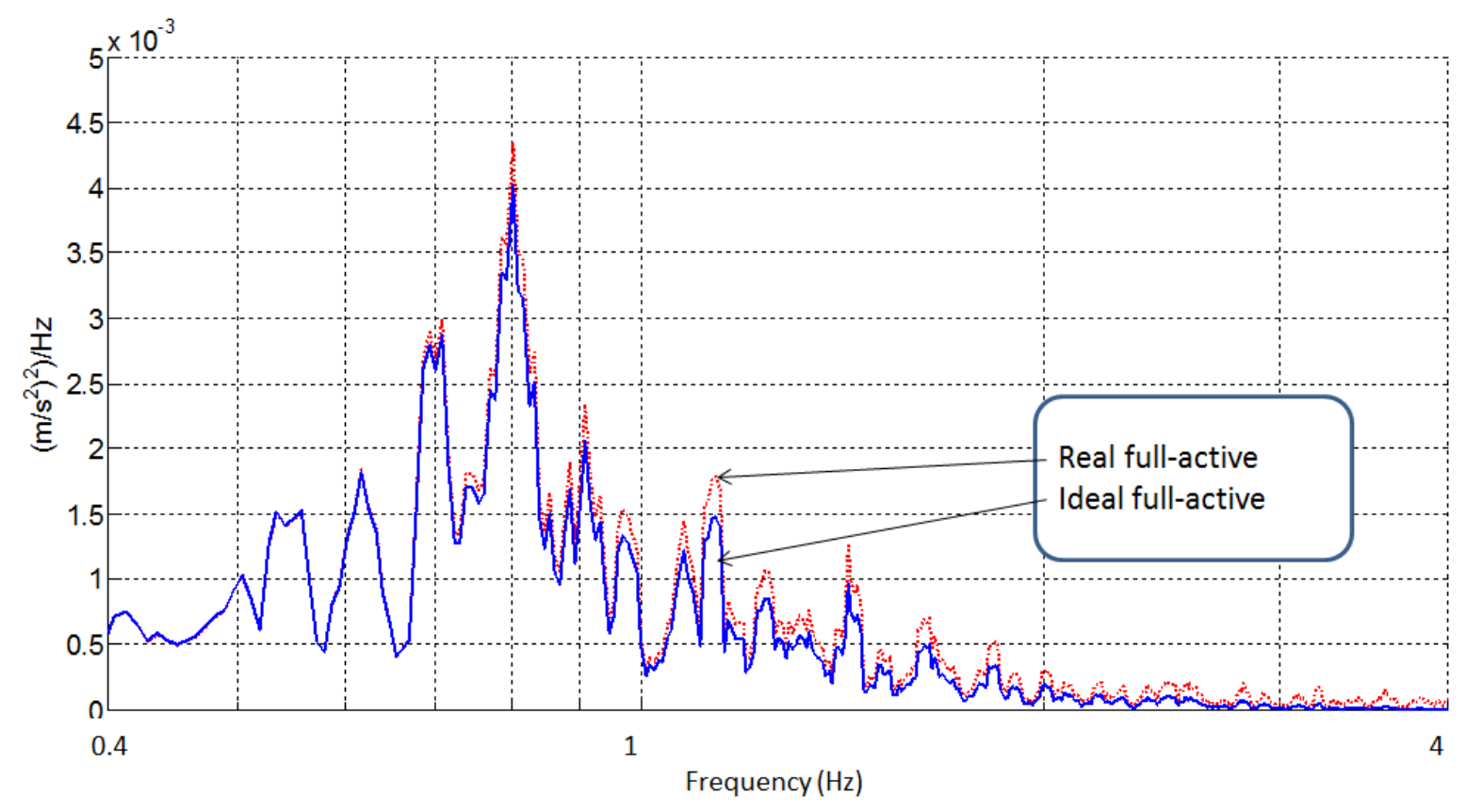

Fig 15 Acceleration PSDs at rear of vehicle, ideal v. real full-active 


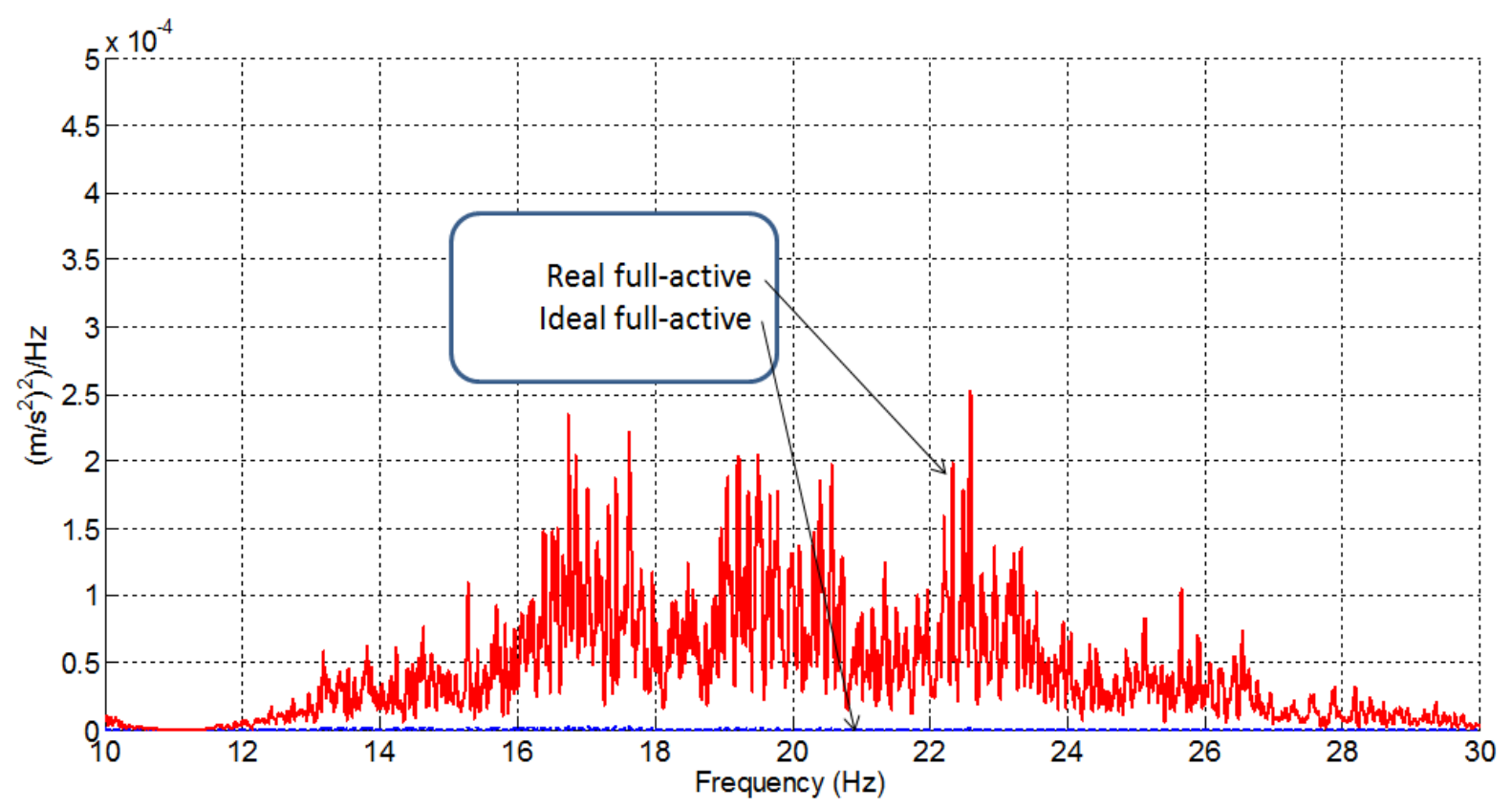

Fig 16 PSDs at rear of vehicle, ideal v. real full-active (30Hz frequency range)

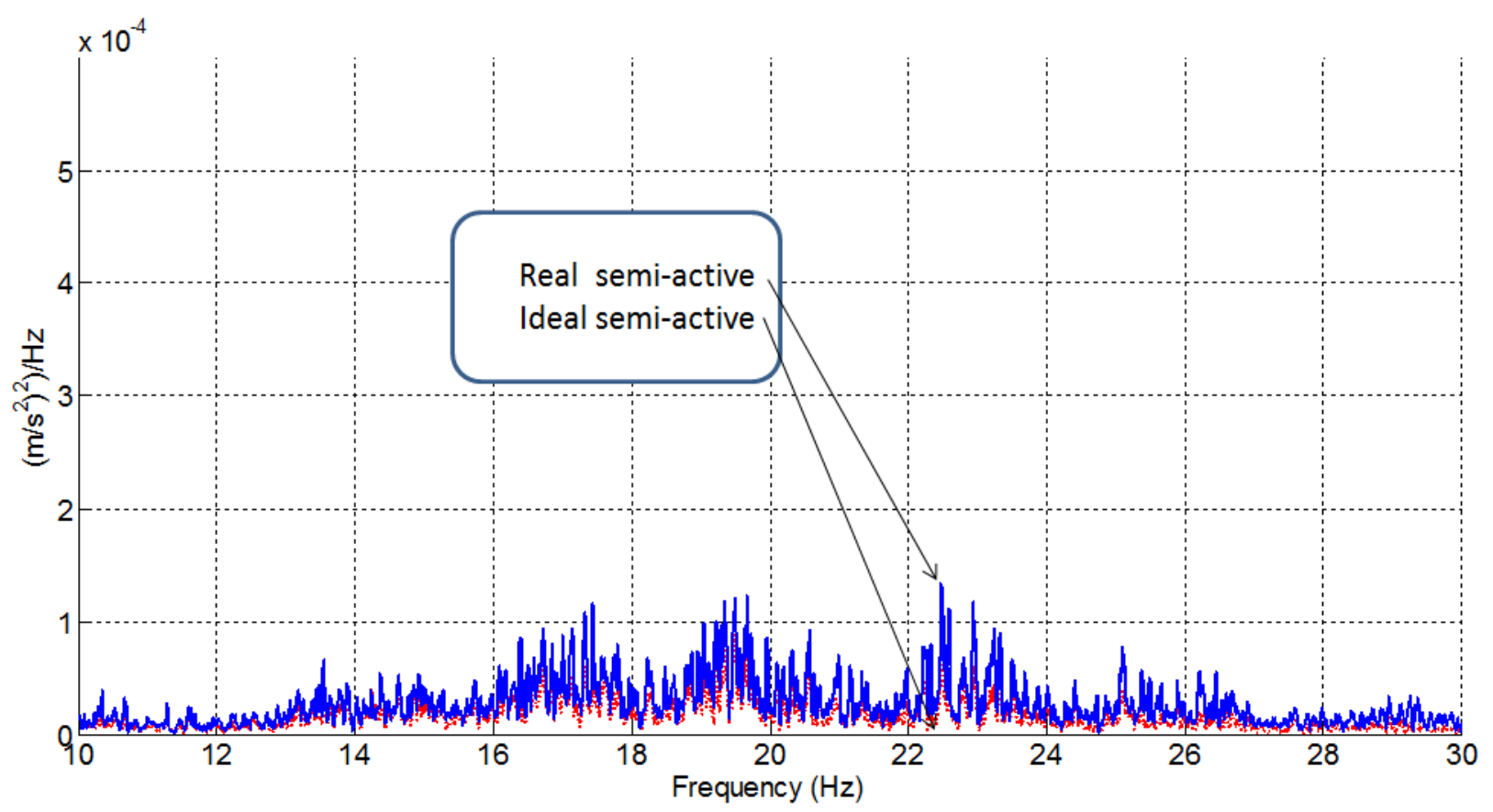

Fig 17 PSDs at rear of vehicle, ideal v. real semi-active (30Hz frequency range)

\subsection{Overall summary}

Table 1 is the principal outcome of the research study and effectively answers the research question regarding the relative performance of the control options. It is also useful to present 
the percentage improvements in the context of the overall problem as set out in Figure 1, and Figure 18 indicates the performance benefits based upon the average improvement (front, centre and rear).

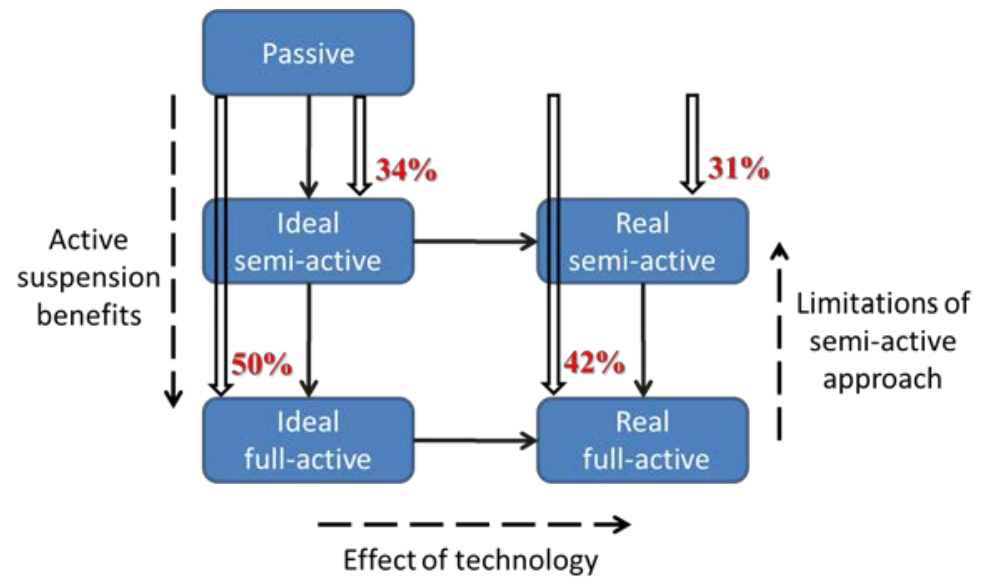

Figure 18 Overall performance summary

The average improvement (percentage reduction in RMS acceleration) across the vehicle is $50.2 \%$ for full-active compared with $34 \%$ for semi-active, and the effect of actuator technology is to change these to $42 \%$ and $30.8 \%$ for full- and semi-active respectively.

\section{CONCLUSIONS}

The study provides a rigorous assessment of the relative benefits of full- active versus semi-active suspension approaches for the vertical suspension of a railway vehicle. It is clear that full-active provides more improvements in ride quality, but semi-active can certainly provide improvements throughout the vehicle. The results provide a basis for understanding the trade-off between the additional ride quality benefits of the full-active approach set against the greater complexity.

Further work should consider other actuator technologies, in particular electro-mechanical, although the characteristics make this less practical as a semi-active solution. It is also necessary to repeat the assessment for the lateral secondary suspension so that a full picture of 
the relative benefits of full- and semi-active suspensions can be completed.

Acknowledgements

This work was carried out mainly at Loughborough University by the second-named author as his dissertation project for Technical University of Vienna. The authors wish to acknowledge the important support by Prof Andreas Kugi who was the official supervisor of the project.

\section{References}

1. Bruni, S., Goodall, R., Mei, T. X. and Tsunashima, H. (2007) Control and monitoring for railway vehicle dynamics, Vehicle System Dynamics, 45:7, 743 - 779

2. Goodall, R. M., Pearson, J. T., Pratt, I. (1993), Actuator Technologies for Secondary Active Suspensions on Railway Vehicles. Proc. International Conference on Speedup Technology for Railway and Maglev Vehicles, Japan Society of Mechanical Engineers, Yokohama

3. Goodall, R. M., Mei, T. X. (2006) “Active Suspensions” in Handbook of Railway Vehicle Dynamics, Swets and Zeitlinger

4. O'Neill, H. R., \& Wale, G. D. (1994). Semi-active suspension improves rail vehicle ride. Computing \& Control Engineering Journal, 5(4), 183-188.

5. Fischer, D., \& Isermann, R. (2004). Mechatronic semi-active and active vehicle suspensions. Control Engineering Practice, 12(11), 1353-1367

6. Kemmetmuller, W. and Kugi, A, (2010) Immersion and invariance-based impedance control for electrohydraulic systems, Int. J. Robust Nonlinear Control 20:725-744

7. Foo, E., \& Goodall, R. M. (2000). Active suspension control of flexible-bodied railway vehicles using electro-hydraulic and electro-magnetic actuators. Control Engineering Practice, 8(5), 507-518

8. Neal, T.P. (1974) Performance estimation for electro-hydraulic control systems, Moog Technical Bulletin 126.

9. Li, H. and Goodall, R.M., (1999) 'Linear and Non-linear Skyhook Damping Control Laws for Active Railway Suspensions', Control Engineering Practice, 7, 1999, pp 843-850 


\section{APPENDIX - Modelling details}

\section{Suspension equations}

$$
\begin{aligned}
& \ddot{z}=\frac{1}{m_{B}}\left(-k_{S e c}\left(2 z-z_{1}-z_{2}\right)+F_{a 1}+F_{a 2}\right) \\
& \ddot{\Theta}=\frac{y_{b}}{I_{x x B}}\left(-k_{S e c}\left(2 y_{b} \Theta-z_{1}+z_{2}\right)+F_{a 1}-F_{a 2}\right) \\
& \ddot{z}_{i}=\frac{1}{m_{b}}\left(k_{S e c}\left(z+y_{b} \Theta-z_{i}\right)-k_{P r i}\left(2 z_{i}-z_{i 1}-z_{i 1}\right)-c_{P r i}\left(2 v_{i}-v_{i 1}-v_{i 2}\right)-F_{a i}\right) \\
& \ddot{\Theta}_{i}=\frac{y_{w}}{I_{x x b}}\left(-k_{P r i}\left(2 y_{w} \Theta_{i}-z_{i 1}+z_{i 2}\right)-c_{P r i}\left(2 y_{w} \omega_{1}-v_{i 1}+v_{i 2}\right)\right)
\end{aligned}
$$

where $\mathrm{z}$ and $\Theta$ are body vertical and pitch displacements, and $\mathrm{z}_{\mathrm{i}}$ and $\Theta_{\mathrm{i}}$ are bogie vertical and pitch displacements with $i \in[1,2]$

\section{Table A1 Suspension parameters}

\begin{tabular}{lll}
\hline Description & Notation & Value \\
\hline Mass of the vehicle & $\mathrm{m}_{\mathrm{B}}$ & $38,000 \mathrm{~kg}$ \\
Body pitch Inertia & $\mathrm{I}_{\mathrm{xxB}}$ & $2.31 \times 10^{6} \mathrm{kgm}^{2}$ \\
Mass of the bogie frame & $\mathrm{m}_{\mathrm{b}}$ & $2,500 \mathrm{~kg}$ \\
Bogie frame pitch Inertia & $\mathrm{I}_{\mathrm{xxb}}$ & $2.604 \times 10^{3} \mathrm{kgm}^{2}$ \\
Semi longitudinal spacing of the sec. susp. & $\mathrm{y}_{\mathrm{b}}$ & $9 \mathrm{~m}$ \\
Semi longitudinal spacing of the wheelsets & $\mathrm{y}_{\mathrm{w}}$ & $1.25 \mathrm{~m}^{-1}$ \\
Secondary spring stiffness per bogie & $\mathrm{k}_{\mathrm{Sec}}$ & $508 \mathrm{kNm}^{-1}$ \\
Secondary damping stiffness per bogie & $\mathrm{k}_{\mathrm{Sec}}$ & $1.016 \mathrm{MNm}^{-1}$ \\
Secondary passive damping per bogie & $\mathrm{C}_{\mathrm{Sec}}$ & $64.11 \mathrm{kNsm}^{-1}$ \\
Primary spring stiffness per axle & $\mathrm{k}_{\mathrm{Pri}}$ & $4.935 \mathrm{MNm}^{-1}$ \\
Primary passive damping per axle & $\mathrm{C}_{\mathrm{Pri}}$ & $50.74 \mathrm{kNsm}^{-1}$ \\
\hline
\end{tabular}

\section{Full active actuator - equations}

$$
\begin{aligned}
& \frac{d}{d t} p_{1}(t)=-\beta \frac{A_{1} v_{p}-q_{1}}{V_{01}+A_{1} z_{p}} \quad \text { and } \quad q_{1}= \begin{cases}\alpha A_{o}\left(\left|x_{v}\right|\right) \sqrt{\frac{2}{\rho}} \sqrt{p_{s}-p_{1}} & \text { for } x_{v}>0 \\
-\alpha A_{o}\left(\left|x_{v}\right|\right) \sqrt{\frac{2}{\rho}} \sqrt{p_{1}-p_{t}} & \text { for } x_{v} \leq 0\end{cases} \\
& \frac{d}{d t} p_{2}(t)=\beta \frac{A_{2} v_{p}-q_{2}}{V_{02}-A_{2} z_{p}} \quad q_{2}= \begin{cases}\alpha A_{o}\left(\left|x_{v}\right|\right) \sqrt{\frac{2}{\rho}} \sqrt{p_{2}-p_{t}} & \text { for } x_{v}>0 \\
-\alpha A_{o}\left(\left|x_{v}\right|\right) \sqrt{\frac{2}{\rho}} \sqrt{p_{s}-p_{2}} & \text { for } x_{v} \leq 0\end{cases}
\end{aligned}
$$

Where the piston velocity is $\mathrm{v}_{\mathrm{p}}$ and $A_{o}\left(\left|x_{v}\right|\right)$ signifies the opening area of the valve and $x_{v}$ is the 
valve position.

The load pressure is defined by the difference of the pressure in the chambers $p_{L}=p_{1}-p_{2}$, where the sum is constant and equal to the supply pressure $p_{s}=p_{1}+p_{2}$. The load flow $q_{L}=\frac{q_{1}+q_{2}}{2}$ is simply the average flow through the valve. By means of these definitions the differential equations of the chamber pressures result in one differential equation for the load pressure which is given by

$$
q_{L}=A_{F} d v+\dot{p}_{L} \frac{V_{t}}{4 \beta}
$$

where $A_{F}=\frac{A_{1}+A_{2}}{2}$ is the area of the piston and $V_{t}=V_{01}+V_{02}$ is the entire volume.

\section{Table A2 Full active actuator parameters}

\begin{tabular}{lll}
\hline Description & Notation & Value \\
\hline Effective area of cylinder & $\mathrm{A}_{\mathrm{F}}$ & $10.66 \times 10^{-4} \mathrm{~m}^{2}$ \\
Chamber volumes of cylinder & $\mathrm{V}_{01}, \mathrm{~V}_{02}$ & $1.066 \times 10^{-4} \mathrm{~m}^{3}$ \\
Constant discharge coefficient & $\mathrm{A}$ & 0.7 \\
Bulk modulus of the oil & $\beta$ & $1.38 \times 10^{9} \mathrm{~Pa}$ \\
Density of the oil & $\rho$ & $858.2 \mathrm{kgm}^{-3}$ \\
Area gradient of the valve & $\mathrm{D}$ & $5.6734 \times 10^{-6} \mathrm{~m}^{2} / \%$ \\
Supply pressure & $\mathrm{P}_{\mathrm{s}}$ & $210 \times 10^{5} \mathrm{~Pa}$ \\
Tank pressure & $\mathrm{P}_{\mathrm{T}}$ & $\sim 0 \mathrm{~Pa}$ \\
Flow gain & $\mathrm{K}_{\mathrm{q}}$ & $0.01196 \mathrm{~m}^{3} \mathrm{~s}^{-1} / \%$ \\
Flow pressure sensitivity & $\mathrm{K}_{\mathrm{c}}$ & $4.492 \times 10^{-13} \mathrm{~m}^{3} \mathrm{~s}^{-1} \mathrm{~Pa}^{-1}$ \\
Unit conversion gain & $\mathrm{K}_{\mathrm{a}}$ & $33.333 \% / \mathrm{A}$ \\
Damping of the servo-valve & $\zeta_{\mathrm{VF}}$ & 0.3 \\
Undamped natural freq. of the servo-valve & $\omega_{\mathrm{VF}}$ & $2 \pi \times 100 \mathrm{rad} / \mathrm{sec}$ \\
\hline
\end{tabular}


Table A3 Semi-active actuator parameters

\begin{tabular}{lll}
\hline Description & Notation & Value \\
\hline Effective area of cylinder & $\mathrm{A}_{\mathrm{S}}$ & $60.23 \times 10^{-4} \mathrm{~m}^{2}$ \\
Chamber volumes of cylinder & $\mathrm{V}_{\mathrm{tS}}$ & $6.023 \times 10^{-4} \mathrm{~m}^{3}$ \\
Bulk modulus of the oil & $\beta$ & $1.38 \times 10^{9} \mathrm{~Pa}$ \\
Damping of the servo-valve & $\zeta_{\mathrm{VS}}$ & 0.3 \\
Undamped natural freq. of the bypass-valve & $\omega_{\text {Vs }}$ & $2 \pi \times 50 \mathrm{rad} / \mathrm{sec}$ \\
\hline
\end{tabular}

\section{Table A4 Controller parameters}

\begin{tabular}{lll}
\hline Description & Notation & Value \\
\hline Damping ratio of the high pass filter & $\zeta_{\mathrm{HPF}}$ & 0.7 \\
Cut off frequency of the high pass filter & $\omega_{\mathrm{HPF}}$ & $1 \mathrm{rad} / \mathrm{sec}$ \\
Bounce mode skyhook damping coefficient (full-act) & $\mathrm{C}_{\mathrm{bF}}$ & $65 \mathrm{kNsm}^{-1}$ \\
Pitch mode skyhook damping coefficient (full-act) & $\mathrm{C}_{\mathrm{pF}}$ & $100 \mathrm{kNsm}^{-1}$ \\
Bounce mode skyhook damping coefficient (full-act) & $\mathrm{c}_{\mathrm{bS}}$ & $1.4 \times \mathrm{c}_{\mathrm{bF}}$ \\
Pitch mode skyhook damping coefficient (full-act) & $\mathrm{C}_{\mathrm{pS}}$ & $1.8 \times \mathrm{c}_{\mathrm{pF}}$ \\
\hline
\end{tabular}

